\title{
Exposure Assessment of Cadmium in Female Farmers in Cadmium-Polluted Areas in Northern Japan
}

\author{
Hyogo Horiguchi ${ }^{1,2, *}$, Etsuko Oguma ${ }^{1,2}$, Satoshi Sasaki ${ }^{3}$, Kayoko Miyamoto ${ }^{4}$, Yoko Hosoi ${ }^{2}$, \\ Akira Ono ${ }^{1,5}$ and Fujio Kayama ${ }^{2}$ \\ 1 Department of Hygiene, Kitasato University School of Medicine, Kanagawa 252-0374, Japan; \\ oguma@med.kitasato-u.ac.jp (E.O.); a-ono@furukawadenchi.co.jp (A.O.) \\ 2 Department of Environmental and Preventive Medicine, School of Medicine, Jichi Medical University, \\ Tochigi 329-0498, Japan; yk_hosoi2005@yahoo.co.jp (Y.H.); kayamafujio@gmail.com (F.K.) \\ 3 Department of Social and Preventive Epidemiology, School of Public Health, The University of Tokyo, \\ Tokyo 113-0033, Japan; stssasak@m.u-tokyo.ac.jp \\ 4 Department of Registered Dietitian, Koyo Nursing Nutrition College, Koyo Gakuen, Ibaraki 306-0013, Japan; \\ kayokomy@nifty.com \\ 5 Environmental Promotion Department, The Furukawa Battery Co., Ltd., Fukushima 972-8501, Japan \\ * Correspondence: hhyogo@med.kitasato-u.ac.jp
}

Received: 14 April 2020; Accepted: 12 June 2020; Published: 17 June 2020

\begin{abstract}
Akita prefecture is located in the northern part of Japan and has many cadmium-polluted areas. We herein performed an exposure assessment of cadmium in 712 and 432 female farmers in two adjacent cadmium-polluted areas (A and B, respectively), who underwent local health examinations from 2001-2004. We measured cadmium concentrations in 100 food items collected from local markets in 2003. We then multiplied the intake of each food item by its cadmium concentration in each subject to assess cadmium intake from food and summed cadmium intake from all food items to obtain the total cadmium intake. Median cadmium intake levels in areas A and B were 55.7 and $47.8 \mu \mathrm{g} / \mathrm{day}$, respectively, which were both higher than that of the general population and were attributed to local agricultural products, particularly rice. We also calculated weekly cadmium intake per body weight and compared it to the previous provisional tolerable weekly intake reported by the Joint FAO (Food and Agriculture Organization)/WHO (World Health Organization) expert committee on food additives or current tolerable weekly intake in Japan of $7 \mu \mathrm{g} / \mathrm{kg}$ BW/week. Medians in areas A and B were 7.2 and $6.0 \mu \mathrm{g} / \mathrm{kg}$ BW/week, respectively. Similar estimated values were also obtained by the Monte Carlo simulation. These results demonstrated that the cadmium exposure levels among the farmers were high enough to be approximately the tolerable weekly intake.
\end{abstract}

Keywords: cadmium; food; farmer; PTWI (provisional tolerable monthly intake); TWI (tolerable weekly intake); Monte Carlo simulation

\section{Introduction}

Humans are exposed on a daily basis to cadmium $(\mathrm{Cd})$, a toxic heavy metal, mainly through the consumption of food containing $\mathrm{Cd}$. Cd absorbed via food accumulates in the kidneys and may cause renal tubular dysfunction, called $\mathrm{Cd}$ nephropathy, in the inhabitants of Cd-polluted areas [1]. The most severe case of $\mathrm{Cd}$ toxicity is itai-itai disease, which is characterized by osteomalacia and renal anemia. It develops among patients with Cd nephropathy [2]. The heaviest Cd-polluted area in Japan was along the Jinzu River basin of Toyama prefecture, at which agricultural fields were contaminated by a large amount of $\mathrm{Cd}$ derived from an upstream mine. A large number of inhabitants in this area developed Cd nephropathy and 200 patients with itai-itai disease were officially recognized by 2020 . 
Although the Cd-polluted area in Toyama was completely restored in 2011, large but scattered Cd-polluted areas still remain in Akita prefecture, which is located in the northern part of Japan, due to the previous activities of mines and smelters [3]. Pollution levels are particularly high in the northern area of Akita prefecture, in which we performed local health examinations on female farmers as part of the Japanese multi-centered environmental toxicant study (JMETS) [4,5]. JMETS aimed for risk assessment of $\mathrm{Cd}$ by targeting females, who are generally more vulnerable to $\mathrm{Cd}$ toxicity than males. Health examinations were sequentially performed in two adjacent areas: the area along Yoneshiro River in Odate city in 2001-2002 (area A) [4] and that upstream of the river in Kazuno city and Kosaka town in 2003-2004 (area B) [5] (Figure 1). Cd pollution levels were higher in area B than in area A because area B was directly affected by two large mines and their affiliated smelters, while area A was secondarily contaminated through irrigation from the river that runs from area $\mathrm{B}$. These studies revealed that many farmers were exposed to high levels of $\mathrm{Cd}$ through the consumption of self-harvested rice contaminated by Cd, some of whom had Cd nephropathy [4-6].

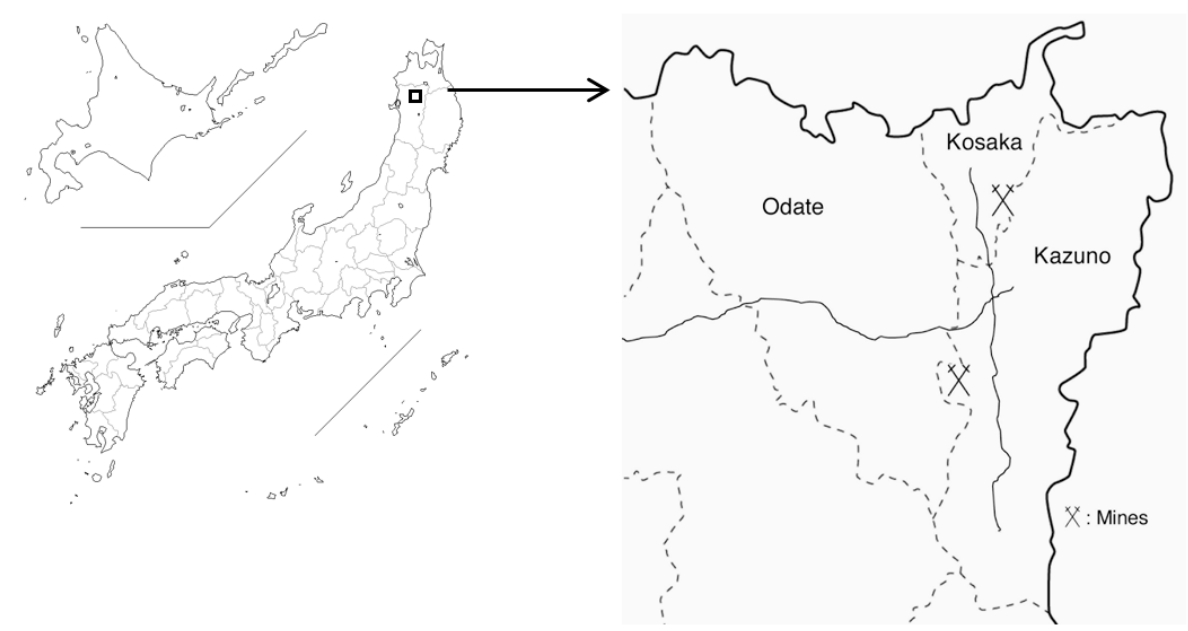

Figure 1. A map of area A (Odate city) and area B (Kazuno city and Kosaka town) in Akita, and their location in Japan (cited from CraftMAP). The thick solid line, dotted lines, and thin solid lines indicate the prefectural boundary, boundaries of municipalities, and courses of the river, respectively.

The provisional tolerable monthly intake (PTMI) of Cd reported by the Joint FAO (Food and Agriculture Organization)/WHO (World Health Organization) expert committee on food additives (JECFA) is now $25 \mu \mathrm{g} / \mathrm{kg} / \mathrm{month}$ and was amended from the provisional tolerable weekly intake (PTWI) of $7 \mu \mathrm{g} / \mathrm{kg} /$ week in 2010 [7]. In Japan, the tolerable weekly intake (TWI) of Cd of $7 \mu \mathrm{g} / \mathrm{kg} /$ week remains in effect and was set by the Food Safety Commission of Japan (FSCJ) in 2008. In our previous study on area A in 2001, we performed dietary exposure assessments on Cd in subjects undergoing health examinations and obtained weekly Cd intake levels for comparisons with the PTWI of Cd at that time [4]. The findings revealed that $33-51 \%$ of subjects had Cd intake levels in excess of the PTWI. However, the exposure assessment was performed using a simplified method based on Cd concentrations in rice and miso, fermented soybean paste, and the consumption of these two foods to estimate individual $\mathrm{Cd}$ intake according to average Japanese $\mathrm{Cd}$ intake levels. Therefore, a more detailed exposure assessment of $\mathrm{Cd}$ is needed in this area to clarify the actual status of dietary $\mathrm{Cd}$ exposure in its inhabitants. A similar exposure assessment of $\mathrm{Cd}$ in area $\mathrm{B}$, in which $\mathrm{Cd}$ pollution was heavier than in area $\mathrm{A}$, needs to be conducted.

In the present study, we collected 100 types of local food items in $2 \mathrm{Cd}$-polluted areas in Akita, measured their $\mathrm{Cd}$ concentrations, and assessed $\mathrm{Cd}$ exposure levels in the subjects of previous local health examinations using an individual food analysis method based on $\mathrm{Cd}$ concentrations in individual food items and the intake amounts of these food items by subjects obtained from diet surveys conducted at health examinations. We also performed the Monte Carlo simulation [8] 
to evaluate the probabilistic distribution of the $\mathrm{Cd}$ intake levels of these subjects in order to confirm the assessment. We demonstrated that Cd intake levels in these subjects were approximately PTWI or TWI, which showed that subjects exposed to $\mathrm{Cd}$ were at risk of adverse effects.

\section{Materials and Methods}

\subsection{Sampling and Handling of Food Items}

We selected approximately 80 local food items from the table of food groups of the Japan's National Health and Nutrition Survey provided by the Ministry of Health, Labor, and Welfare, that were eaten at a high frequency in diet surveys from health examinations conducted on local female farmers in area A in 2001-2002 [4]. We then deleted food items in which Cd concentrations were undetectable in the study on the absorption rate of dietary $\mathrm{Cd}$ among female farmers conducted in the winter of 2002-2003 [9]. We added food items that were assumed to have high Cd concentrations, such as seaweed, shellfish, mollusks, and livers, based on a previous study [10]. In November and December 2003, we purchased these food items at local markets in areas A and B based on the recommendations of a local female farmer who was familiar with traditional dietary patterns. We collected 100 food items for the measurement of $\mathrm{Cd}$ concentrations. We aimed to collect three of each food item in each area; however, this number increased or decreased depending on the inventory status. Therefore, the number of purchases ranged between 1 and 10, with an average of six. We collected $100 \mathrm{~g}$ of the edible portions of each food item and stored them at room temperature, $4{ }^{\circ} \mathrm{C}$, or $-20^{\circ} \mathrm{C}$ depending on their perishability until the measurement of $\mathrm{Cd}$ concentrations.

\subsection{Measurement of $\mathrm{Cd}$ Concentrations}

The measurement of Cd concentrations in food items, except for rice, was conducted by Japan Food Research Laboratories (Tokyo, Japan). Next, 10 to $20 \mathrm{~g}$ of the edible portion of food, which was precisely measured in a Kjeldahl flask, was added to $200 \mathrm{~mL}$ of nitric acid $\left(\mathrm{HNO}_{3}\right)$ and heated. After the vigorous reaction was completed, $5 \mathrm{~mL}$ of sulfuric acid $\left(\mathrm{H}_{2} \mathrm{SO}_{4}\right)$ was added to the flask and heated again until the color changed to light yellow. After cooling, the inside of the flask was washed well with deionized water (less than $1 \mu \mathrm{s} / \mathrm{cm}$ of conductance) and heated again until $\mathrm{H}_{2} \mathrm{SO}_{4}$ was released as white smoke. The residual was then dissolved in an appropriate quantity of deionized water to make a sample solution. The solution was moved to a separatory funnel and $10 \mathrm{~mL}$ of $50 \%$ diammonium hydrogen citrate and Thymol blue indicator $(0.1 \mathrm{~g}$ of Thymol blue in $100 \mathrm{~mL}$ of ethyl alcohol) were then added. After neutralization with ammonium solution, the volume of the solution was increased to $100 \mathrm{~mL}$ by the addition of deionized water, and this was followed by $5 \mathrm{~mL}$ of $3 \%$ ammonium pyrrolidine-N-dithiocarbamate (APDC) solution/ammonium sulfate and $10 \mathrm{~mL}$ of butyl acetate with shaking for $5 \mathrm{~min}$. After being left to stand, the butyl acetate layer was collected for the measurement of $\mathrm{Cd}$ concentrations using a flame atomic absorption spectrometer (AA-890, Nippon Jarrell-Ash Co., Ltd., Tokyo, Japan). The original standard Cd solution (Kanto Chemical Co., Inc., Tokyo, Japan) was diluted with $1 \%$ hydrochloric acid $(\mathrm{HCl})$ to make 0.4 and $0.8 \mu \mathrm{g} / \mathrm{mL}$ standard $\mathrm{Cd}$ solutions. Quality control was achieved in the analysis using sugar (commercial products) added with $\mathrm{Cd}$ as an alternative to certified reference materials. Its additional recovery was maintained within 90-110\%. The detection limits for cereals, other food items, and drinking water were $0.01 \mathrm{mg} / \mathrm{kg}$, $0.005 \mathrm{mg} / \mathrm{kg}$, and $0.001 \mathrm{mg} / \mathrm{L}$, respectively.

\subsection{Health Examinations and Diet Surveys}

Health examinations performed on female farmers in areas A and B in 2001-2004 were described previously [4.5]. In the present study, we used data obtained on age, height, weight, and the results of a diet history questionnaire (DHQ) from 725 and 438 subjects in areas A and B, respectively. $\mathrm{DHQ}$ is designed to assess food and nutrient intake levels in the previous month based on the quantity and semiquantitative frequency of the consumption of 110 food items commonly eaten in Japan [11]. 
Estimates of intake for food, energy, and selected nutrients were calculated using an ad hoc computer algorithm for DHQ based on Standard Tables of Food Composition in Japan, which has already been validated $[12,13]$. We used data obtained on individual food intake levels to calculate Cd intake levels. Among subjects, 12 and 6 with extremely low or high energy intake levels ( $\leq 1000$ or $\geq 3500 \mathrm{kcal} / \mathrm{day}$ ) were excluded in areas $A$ and $B$, respectively, in addition to one whose consumption of rice was zero in area A, resulting in 712 and 432 subjects for analyses.

\subsection{Calculation of Cd Intake Levels}

We calculated the Cd intake levels of individual subjects by multiplying the intake of each food item by its $\mathrm{Cd}$ concentration and then summed $\mathrm{Cd}$ intake levels from all foods consumed. However, the food items for which intake levels were assessed by DHQ and those for which Cd concentrations were measured were not always in one-to-one correspondence. Therefore, we adjusted mismatches for reconciliation, as described below. Regarding boiled barley-rice, which is assumed to consist of $70 \%$ rice and $30 \%$ wheat, the $\mathrm{Cd}$ concentrations of rice and wheat flour, respectively, were multiplied. Since the intake levels of udon (wheat noodles) and soba (buckwheat noodles) were collectively assessed by DHQ, they were divided into two halves, each of which was multiplied by the Cd concentration of udon or soba. The intake levels of various noodles, including Chinese noodles or spaghetti, which were separately assessed by DHQ, were multiplied by the Cd concentration of udon, assuming that these foods were similarly made of wheat flour. The intake levels of butter rolls, croissants, pizza, pancakes, and okonomiyaki (Japanese-style pancakes) were also multiplied by the Cd concentration of white bread, while those of snack foods, Japanese sweets, cakes, cookies, and doughnuts were multiplied by the Cd concentration of manju (Japanese sweet bun). Regarding sweet potatoes, taro, yams, and Chinese yams, which were assessed collectively by DHQ, the average Cd concentration of sweet potatoes, taro, and yams was used. The average $\mathrm{Cd}$ concentration of silken and cotton tofu was used for tofu (soybean curd). The average $\mathrm{Cd}$ concentration of spinach, garland chrysanthemum, Japanese mustard spinach, Bok choy (Chinese cabbage), and Japanese leek was used for leafy green vegetables, which were collectively assessed by DHQ. Concerning the intake of wakame seaweed, the $\mathrm{Cd}$ concentration of raw wakame seaweed was used. The intake of mushrooms was evenly divided into shiitake mushroom and other mushrooms, and the Cd concentrations of shiitake mushroom and maitake mushroom were multiplied. Regarding the intake of shrimp and fish eggs, the average $\mathrm{Cd}$ concentrations of prawns and shrimp and of cod and salmon roe, respectively, were used. Since the intake of shellfish included oysters and other shellfish in DHQ, the Cd concentrations of oysters with innards and the average $\mathrm{Cd}$ concentrations of scallops without innards, Japanese littleneck clams, and freshwater clams were respectively multiplied. The average $\mathrm{Cd}$ concentration of beef liver, pork liver, chicken liver, Hinai chicken liver, and the innards of Hinai chicken was used for the intake of liver. Food items for which Cd concentrations were not detected, such as animal meat, eggs, milk, and green tea (after brewing), were not included in the calculation of total Cd intake. Cd intake from garlic, okra, belvedere fruit, kelp, hijiki seaweed, agar-agar, mozuku seaweed, and scallops with innards was also excluded because they were not evaluated by DHQ; however, their Cd concentrations were measured. The arithmetic means (AMs) of the Cd concentrations of these food items from both areas were multiplied by their corresponding food intake, while rice $\mathrm{Cd}$ concentrations in individual subjects, which were obtained in previous health examinations, were used to calculate individual $\mathrm{Cd}$ intake from rice. When a subject consumed brown rice, the $\mathrm{Cd}$ concentration of which is generally reduced by $10 \%$ due to polishing [14], the $\mathrm{Cd}$ concentration adjusted to be equivalent to polished rice was multiplied for calculations. One rice sample was missing in area A, which was substituted with the geometric mean (GM) of the $\mathrm{Cd}$ concentration in rice. The $\mathrm{Cd}$ concentrations of some foods with masses that are changed by cooking were corrected using the table of mass changes in individual food items from the Standard Tables of Food Compositions in Japan (7th edition, Japanese Ministry of Education, Culture, Sports, Science and Technology). 


\subsection{Statistical Analysis}

Age, height, weight, total energy intake, and rice intake, which followed a normal distribution, were presented as AMs with arithmetic standard deviations (SDs) and differences in their mean values were analyzed by the Student's $t$-test. Since Cd concentrations in rice followed a clear lognormal distribution with large numbers and the distribution of $\mathrm{Cd}$ concentrations in other food items was not clear because of small numbers, rice and other food items were shown as GMs and AMs, respectively. $\mathrm{Cd}$ intake levels with skewed distributions were presented as medians with 25th and 75th percentiles and differences in their median values were analyzed by the median test. The $\chi^{2}$ test was used to compare the proportions of Cd intake per body weight above the PTWI or TWI. Regarding multiple comparisons, the Steel-Dwass test was performed to compare the medians of age-classified Cd intake. The judgment of outliers was made using the Smirnov-Grubbs test. After the exclusion of outliers, the Monte Carlo simulation was performed on weekly Cd intake levels with 10,000 repetitions of the calculation based on the supposition of a lognormal distribution. Statistical analyses were performed using IBM SPSS Statistics V25 (SPSS Japan, Tokyo, Japan) based on the basic management of data by Mac Excel Tokei ver. 2.0 (Esumi, Tokyo, Japan).

\section{Results}

Food items and their Cd concentrations, divided into 10 subgroups, are listed in Tables 1-10. $\mathrm{Cd}$ concentrations in rice and rice products were high (Table 1 ). The average $\mathrm{Cd}$ concentrations in rice, 0.158 and $0.109 \mathrm{mg} / \mathrm{kg}$, were lower than the safety standard of $0.4 \mathrm{mg} / \mathrm{kg}$; however, 8.2 and $5.8 \%$ of rice had $\mathrm{Cd}$ concentrations that were above the safety standard in areas $\mathrm{A}$ and $\mathrm{B}$, respectively. Among cereals, tubers, and roots, while the $\mathrm{Cd}$ concentrations of wheat flour and its products were not high, taro (satoimo in Japanese) had a high Cd concentration of $0.289 \mathrm{mg} / \mathrm{kg}$ (Table 2). The Cd concentrations of soybeans, including edamame, were high, whereas those of their processed foods were not, except for miso (Table 3). Cd was detected in all vegetables investigated, among which spinach, Japanese parsley, garland chrysanthemum, Japanese mustard spinach, and belvedere fruit showed high Cd concentrations (Table 4). Shiitake mushroom and seaweed (wakame, kombu, nori, and hijiki in Japanese) had markedly high Cd concentrations (Tables 5 and 6). Among fish and shellfish, salted squid guts, scallops with innards, oysters with innards, and freshwater clams, all of which had innards, had very high Cd concentrations, while fish meat itself did not (Table 7). Cd was not detected in many livestock food items, such as meat, eggs, and milk, except for the innards (Table 8). Cd was not detected in fruit (Table 9). High Cd concentrations were found in chocolate and tea leaves (Table 10). $\mathrm{Cd}$ was not detected in brewed tea.

We then calculated $\mathrm{Cd}$ intake levels by subjects who underwent health examinations, multiplied $\mathrm{Cd}$ concentrations in food items by individual food intake, and showed the results obtained in subgroups. The backgrounds of subjects in areas A and B, the food intake levels for whom were used to calculate Cd intake levels, are shown in Table 11. No significant differences were observed in age, energy intake, or rice intake between the 2 areas, whereas significant differences were noted in height $(p=0.047)$ and weight $(p=0.047)$, but were biologically negligible.

$\mathrm{Cd}$ intake from seaweed, fish, and shellfish was combined into one subgroup as seafood and that from livestock food was included in the subgroup as others, while that from fruit was excluded from calculations (Table 12). Among the subgroups, Cd intake from the subgroup of rice and rice products was the highest in both areas, and accounted for approximately $40-50 \%$ of the total Cd intake. Cd intake levels from the subgroups of vegetables and seafood were higher than those in the other subgroups. $\mathrm{Cd}$ intake from the subgroup of rice and rice products was significantly higher in area A than in area B, while those from other subgroups were similar between the two areas, except for vegetables, with $\mathrm{Cd}$ intake being significantly lower in area A than in area B. The median total Cd intake levels in areas A and B were 55.7 and $47.8 \mu \mathrm{g} /$ day, respectively, with the former being significantly higher than the latter. 
Table 1. Cadmium (Cd) concentrations in rice and rice products. Data are presented as arithmetic means, except for rice, which are presented as geometric means (GMs).

\begin{tabular}{cccc}
\hline Food Items & $n$ & Cd (mg/kg) & Ranges \\
\hline Rice (area A) & $711^{*}$ & $0.158(\mathrm{GM})$ & $<0.02-0.971$ \\
Rice (area B) & 432 & $0.109(\mathrm{GM})$ & $0.008-0.687$ \\
Kiritampo; pounded & 6 & 0.063 & $0.070-0.102$ \\
rice skewer & 10 & 0.098 & $0.02-0.32$ \\
Glutinous rice & 5 & 0.069 & $0.017-0.182$ \\
Rice cakes & 4 & 0.091 & $0.017-0.263$ \\
Rice crackers & *. One sample is missing
\end{tabular}

*: One sample is missing.

Table 2. Cadmium $(\mathrm{Cd})$ concentrations in cereals, tubers, and roots. Data are presented as arithmetic means.

\begin{tabular}{cccc}
\hline Food Items & $\boldsymbol{n}$ & $\mathbf{C d}(\mathbf{m g} / \mathbf{k g})$ & Ranges \\
\hline White bread & 6 & 0.018 & $0.016-0.023$ \\
Ampan, bean-jam bun & 6 & 0.010 & $0.010-0.014$ \\
Wheat flour & 3 & 0.021 & $0.019-0.024$ \\
Udon; wheat noodles $^{\text {Soba; buckwheat noodles }}$ & 6 & 0.005 & $0.005-0.007$ \\
Sesame seeds & 6 & 0.019 & $0.007-0.034$ \\
Sweet potato & 6 & 0.055 & $0.021-0.11$ \\
Potato & 6 & 0.008 & $0.005-0.016$ \\
Taro & 6 & 0.034 & $0.005-0.098$ \\
Yams, Chinese yams & 7 & 0.289 & $0.036-0.795$ \\
Potato chips * & 3 & 0.061 & $0.005-0.167$ \\
& *: Only from area A. & $0.029-0.114$ \\
\hline
\end{tabular}

Table 3. Cadmium (Cd) concentrations in soybeans and soybean products. Data are presented as arithmetic means.

\begin{tabular}{cccc}
\hline Food Items & $\boldsymbol{n}$ & $\mathbf{C d}(\mathbf{m g} / \mathbf{k g})$ & Ranges \\
\hline Soybeans & 4 & 0.115 & $0.05-0.25$ \\
Silken tofu & 5 & 0.015 & $0.009-0.028$ \\
Cotton tofu & 6 & 0.027 & $0.013-0.052$ \\
Deep-fried tofu & 6 & 0.051 & $0.033-0.083$ \\
Natto; fermented soybeans & 6 & 0.028 & $0.011-0.055$ \\
Miso; soybean paste & 6 & 0.123 & $0.026-0.259$ \\
Edamame; soybeans in the pod & 6 & 0.155 & $0.085-0.293$ \\
Soy sauce & 4 & 0.019 & $0.015-0.026$ \\
\hline
\end{tabular}

Table 4. Cadmium (Cd) concentrations in vegetables. Data are presented as arithmetic means.

\begin{tabular}{cccc}
\hline Food Items & $\boldsymbol{n}$ & $\mathbf{C d ~} \mathbf{( m g} / \mathbf{k g})$ & Ranges \\
\hline Carrot & 6 & 0.047 & $0.013-0.107$ \\
Spinach & 6 & 0.064 & $0.030-0.122$ \\
Tomato & 5 & 0.012 & $0.005-0.022$ \\
Squash & 6 & 0.016 & $0.008-0.024$ \\
Broccoli & 6 & 0.012 & $0.005-0.027$ \\
Japanese white radish & 6 & 0.009 & $0.005-0.023$ \\
Onions & 5 & 0.016 & $0.005-0.031$ \\
Cabbage & 6 & 0.008 & $0.006-0.011$ \\
Chinese cabbage & 6 & 0.020 & $0.011-0.038$ \\
Burdock & 6 & 0.063 & $0.017-0.212$ \\
\hline
\end{tabular}


Table 4. Cont.

\begin{tabular}{|c|c|c|c|}
\hline Food Items & $n$ & $\mathrm{Cd}(\mathrm{mg} / \mathrm{kg})$ & Ranges \\
\hline Dropwort Japanese parsley & 6 & 0.010 & $0.005-0.019$ \\
\hline Eggplant & 6 & 0.017 & $0.005-0.028$ \\
\hline Garland chrysanthemum & 5 & 0.074 & $0.006-0.244$ \\
\hline Japanese mustard spinach & 5 & 0.065 & $0.009-0.23$ \\
\hline Bok choy (Chinese cabbage) & 5 & 0.029 & $0.01-0.101$ \\
\hline Green pepper & 5 & 0.006 & $0.005-0.009$ \\
\hline Garlic & 6 & 0.051 & $0.01-0.142$ \\
\hline Okra & 3 & 0.023 & $0.012-0.043$ \\
\hline Belvedere fruit & 6 & 0.069 & $0.041-0.095$ \\
\hline Japanese leek * & 3 & 0.032 & $0.005-0.083$ \\
\hline Pickled vegetables & 10 & 0.022 & $0.009-0.095$ \\
\hline Smoked daikon pickles & 6 & 0.024 & $0.017-0.035$ \\
\hline
\end{tabular}

*: Only from area A.

Table 5. Cadmium (Cd) concentrations in mushrooms. Data are presented as arithmetic means.

\begin{tabular}{cccc}
\hline Food Items & $\boldsymbol{n}$ & $\mathbf{C d}(\mathbf{m g} / \mathbf{k g})$ & Ranges \\
\hline Raw shiitake mushroom & 7 & 0.374 & $0.065-0.527$ \\
Maitake mushroom & 6 & 0.043 & $0.023-0.108$ \\
\hline
\end{tabular}

Table 6. Cadmium (Cd) concentrations in seaweed and seaweed products. Data are presented as arithmetic means.

\begin{tabular}{cccc}
\hline Food Items & $n$ & Cd $(\mathbf{m g} / \mathbf{k g})$ & Ranges \\
\hline Wakame seaweed (raw) & 6 & 0.253 & $0.069-0.544$ \\
Wakame seaweed (dried) & 3 & 4.64 & $4.11-5.06$ \\
Kelp (konbu seaweed) & 6 & 0.682 & $0.119-1.78$ \\
Laver (nori seaweed) & 4 & 0.413 & $0.209-0.66$ \\
Hijiki seaweed & 5 & 1.066 & $0.693-1.53$ \\
Agar-agar * & 3 & 0.024 & $0.014-0.033$ \\
Mozuku seaweed & 6 & 0.006 & $0.005-0.01$ \\
\hline
\end{tabular}

*: Only from area A.

Table 7. Cadmium (Cd) concentrations in fish and shellfish. Data are presented as arithmetic means.

\begin{tabular}{cccc}
\hline Food Items & $n$ & Cd (mg/kg) & Ranges \\
\hline Salmon & 6 & $<0.005$ & \\
Tuna & 6 & 0.009 & $0.005-0.013$ \\
Cod & 6 & $<0.005$ & \\
Horse mackerel & 6 & 0.012 & $0.007-0.015$ \\
Mackerel & 6 & 0.012 & $0.005-0.018$ \\
Sandfish without eggs & 6 & 0.012 & $0.009-0.017$ \\
Sandfish with eggs & 6 & 0.014 & $0.01-0.018$ \\
Squid & 6 & 0.032 & $0.018-0.081$ \\
Salted squid guts & 5 & 2.36 & $0.978-6.57$ \\
Octopus & 6 & 0.007 & $0.005-0.011$ \\
Prawn & 7 & 0.055 & $0.005-0.17$ \\
Shrimp * & 2 & 0.022 & $0.009-0.035$ \\
Cod roe & 6 & 0.008 & $0.005-0.015$ \\
Salmon roe & 3 & $<0.005$ & \\
\hline
\end{tabular}


Table 7. Cont

\begin{tabular}{cccc}
\hline Food Items & $\boldsymbol{n}$ & $\mathbf{C d}(\mathbf{m g} / \mathbf{k g})$ & Ranges \\
\hline Scallops without innards & 5 & 0.0408 & $0.012-0.103$ \\
Scallops with innards & 5 & 3.635 & $0.684-5.54$ \\
Oysters with innards & 6 & 0.680 & $0.486-1.03$ \\
Japanese littleneck clam & 4 & 0.160 & $0.028-0.305$ \\
Freshwater clam & 4 & 0.375 & $0.235-0.55$ \\
Hampen (fish minced and steamed) & 6 & 0.005 & $0.005-0.006$ \\
Dried whitebait & 6 & 0.010 & $0.005-0.02$ \\
Broiled eel & 6 & 0.008 & $0.005-0.011$ \\
\hline
\end{tabular}

*: Only from area B.

Table 8. Cadmium (Cd) concentrations in livestock food. Data are presented as arithmetic means.

\begin{tabular}{cccc}
\hline Food Items & $n$ & Cd $(\mathbf{m g} / \mathbf{k g})$ & Ranges \\
\hline Beef & 6 & $<0.005$ & \\
Pork & 5 & $<0.005$ & \\
Chicken & 4 & $<0.005$ & \\
Hinai chicken & 5 & $<0.005$ & \\
Horse meat & 3 & 0.006 & $0.005-0.007$ \\
Beef liver * & 1 & 0.021 & \\
Pork liver & 4 & 0.024 & $0.016-0.028$ \\
Chicken liver & 5 & 0.015 & $0.01-0.022$ \\
Hinai chicken liver * & 2 & 0.039 & $0.033-0.044$ \\
Innards of Hinai chicken & 6 & 0.021 & $0.008-0.066$ \\
Sausage & 3 & 0.006 & $0.005-0.008$ \\
Egg & 6 & $<0.005$ & \\
Milk & 6 & $<0.005$ & \\
\multicolumn{4}{c}{ *: Only from area A. }
\end{tabular}

Table 9. Cadmium (Cd) concentrations in fruit. Data are presented as arithmetic means.

\begin{tabular}{cccc}
\hline Food Items & $\boldsymbol{n}$ & Cd $(\mathbf{m g} / \mathbf{k g})$ & Ranges \\
\hline Apple & 6 & $<0.005$ & \\
Apple juice & 6 & $<0.005$ & \\
Kiwi fruit & 5 & $<0.005$ & \\
\hline
\end{tabular}

Table 10. Cadmium (Cd) concentrations in others. Data are presented as arithmetic means.

\begin{tabular}{cccc}
\hline Food Items & $n$ & Cd (mg/kg) & Ranges \\
\hline Manju; sweet bun & 10 & 0.022 & $0.010-0.127$ \\
Chocolate * & 3 & 0.042 & $0.03-0.084$ \\
Curry roux * & 3 & 0.015 & $0.012-0.018$ \\
Flavor seasonings * & 1 & 0.025 & \\
Ketchup & 3 & 0.016 & $0.016-0.017$ \\
Japanese green tea leaves & 3 & 0.026 & $0.009-0.049$ \\
$*$ & & & \\
Nutritional supplement & 3 & $<0.005$ & \\
drink * & 7 & $<0.005$ & \\
Well water * & 7 &
\end{tabular}

*: Only from area A. 
Table 11. Backgrounds of female farmers who underwent health examinations in areas A and B.

\begin{tabular}{ccccc}
\hline \multirow{2}{*}{ Backgrounds } & \multicolumn{2}{c}{ Area A $(n=712)$} & \multicolumn{2}{c}{ Area B $(n=432)$} \\
\cline { 2 - 5 } & Mean \pm SD & Ranges & Mean \pm SD & Ranges \\
\hline Age & $57.4 \pm 11.3$ & $21-79$ & $57.2 \pm 9.3$ & $35-82$ \\
Height $(\mathrm{cm})$ & $152.0 \pm 6.2$ & $130-180$ & $152.8 \pm 5.9^{*}$ & $132-169$ \\
Weight $(\mathrm{kg})$ & $54.5 \pm 8.0$ & $34-92$ & $55.5 \pm 8.5^{*}$ & $33-94$ \\
Energy intake & $1933.7 \pm 463.7$ & $1000-3440$ & $1923.8 \pm 459.0$ & $1047-3451$ \\
$\quad(k c a l /$ day $)$ & $371.8 \pm 118.9$ & $78.6-1120$ & $359.0 \pm 105.3$ & $30-880$ \\
Rice intake $(\mathrm{g} /$ day) & $*: p<0.05$ versus area A (unpaired Student's $t$-test).
\end{tabular}

Table 12. Daily cadmium intake per person ( $\mu \mathrm{g} /$ day) in female farmers in areas A and B.

\begin{tabular}{ccccc}
\hline \multirow{2}{*}{ Subgroups of Cadmium Intake } & \multicolumn{2}{c}{ Area A $(n=712)$} & \multicolumn{2}{c}{ Area B $(n=432)$} \\
\cline { 2 - 5 } & $\begin{array}{c}\text { Median (25-75th } \\
\text { Percentile) }\end{array}$ & Ranges & $\begin{array}{c}\text { Median (25-75th } \\
\text { Percentile) }\end{array}$ & Ranges \\
\hline Total cadmium intake & $55.7(40.5-75.4)$ & $10.6-301$ & $47.8(34.2-64.5) *$ & $10.2-187$ \\
Rice and rice products & $28.3(17.1-44.7)$ & $0.1-289$ & $19.4(9.9-37.4) *$ & $0.1-154$ \\
Cereals, tubers, and roots & $2.4(1.5-4.3)$ & $0-40.7$ & $2.3(1.4-3.8)$ & $0-13.8$ \\
Soybeans and soybean products & $3.4(2.3-4.6)$ & $0.2-22.6$ & $3.4(2.5-4.5)$ & $0.3-11.1$ \\
Vegetables & $6.2(3.9-9.0)$ & $0.5-26.2$ & $6.8(4.3-9.4) *$ & $0.7-29$ \\
Mushrooms & $2.8(1.1-4.4)$ & $0-39.3$ & $2.6(0.8-4.4)$ & $0-24.6$ \\
Seafood ${ }^{* *}$ & $6.1(3.4-10.9)$ & $0.3-46.5$ & $6.3(3.9-9.9)$ & $0.4-52.2$ \\
Others *** & $0.5(; 0.3-0.9)$ & $0-6.1$ & $0.5(0.3-0.9)$ & $0-5.4$ \\
\hline
\end{tabular}

*: $p<0.05$ versus area A (median test). ${ }^{* *}$ : including seaweed, fish, and shellfish. ${ }^{* * *}$ : including manju, livestock food, chocolate, and flavor seasonings.

We then compared the results obtained with Cd intake by the general population in Japan (Figure 2) [15,16]. Cd intake has been gradually decreasing in Japan: $31.1 \mu \mathrm{g} / \mathrm{day}(16.2 \mu \mathrm{g} / \mathrm{day}$ from rice and $14.9 \mu \mathrm{g} /$ day from other food items) in 1981, $21.1 \mu \mathrm{g} /$ day $(7.8 \mu \mathrm{g} /$ day from rice and $13.3 \mu \mathrm{g} /$ day from other food items) in 2007, and $17.8 \mu \mathrm{g} / \mathrm{day}(5.7 \mu \mathrm{g} / \mathrm{day}$ from rice and $12.1 \mu \mathrm{g} / \mathrm{day}$ from other food items) in 2015. This was mainly attributed to a reduction in Cd intake from rice. Cd intake levels from rice and rice products in areas A $(28.3 \mu \mathrm{g} / \mathrm{day})$ and B $(19.4 \mu \mathrm{g} / \mathrm{day})$ were 3.6- and 2.5-fold higher, respectively, than that $(7.8 \mu \mathrm{g} / \mathrm{day})$ by the general population in 2007 , while $\mathrm{Cd}$ intake levels from other food items in areas A and B (approximately $24.0 \mu \mathrm{g} /$ day) were 1.8-fold higher than that (13.3 $\mu \mathrm{g} /$ day) by the general population. Total Cd intake levels in areas A and B were approximately 2.5 -fold higher than that by the general population.

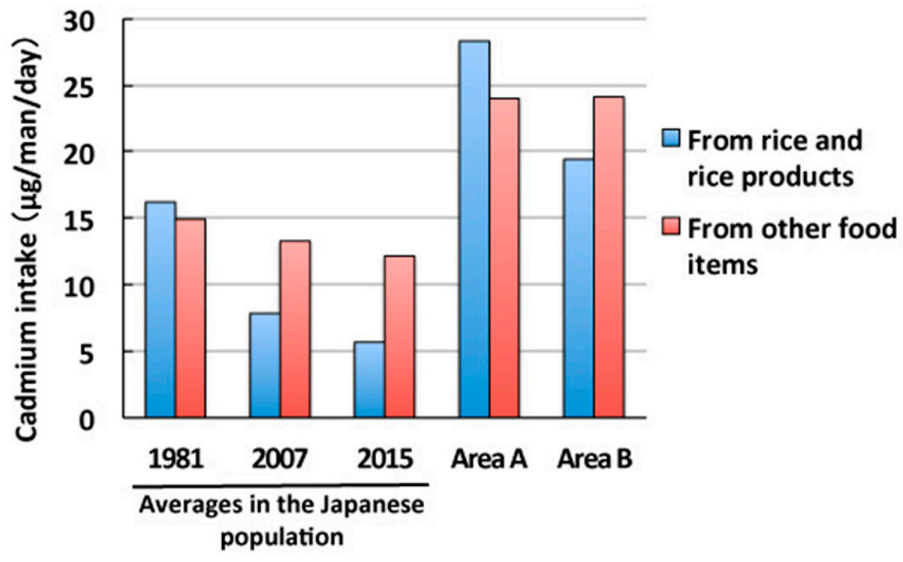

Figure 2. Cadmium intake levels per person from rice and rice products and from others in female farmers in cadmium-polluted areas A and B in Akita, Japan, shown by medians, and comparisons with average cadmium intake in the Japanese population. 
We also calculated weekly $\mathrm{Cd}$ intake per body weight, using individual values of body weight, to compare the PTWI of JECFA at that time or the current TWI in Japan of $7 \mu \mathrm{g} / \mathrm{kg}$ BW/week. Median weekly Cd intake levels were 7.2 and $6.0 \mu \mathrm{g} / \mathrm{kg}$ BW/week in areas A and B, respectively, with both being approximately PTWI or TWI (Table 13). The distributions of weekly Cd intake levels in areas A and B were shown in histograms (Figure 3). The exclusion of data obtained from two subjects in area A that were extremely large and considered to be outliers resulted in similar distributions in both areas that skewed to the higher side. The percentages of subjects with weekly Cd intake levels above PTWI or TWI were 51.7 and $38.0 \%$ in areas A and B, respectively $\left(p<0.05, \chi^{2}\right.$ test) (Table 13).

Table 13. Weekly cadmium intake per body weight ( $\mu \mathrm{g} / \mathrm{kg} \mathrm{BW} /$ week) in female farmers in areas A and $B$ and their distribution.

\begin{tabular}{ccc}
\hline Weekly Cadmium Intake & Area A $(\boldsymbol{n}=\mathbf{7 1 2})$ & Area B $(\boldsymbol{n}=\mathbf{4 3 2})$ \\
\hline Median & 7.2 & $6.0^{*}$ \\
$25-75$ th percentiles & $5.2-9.7$ & $4.4-8.5$ \\
Ranges & $1.5-42$ & $1.3-26$ \\
$<7 \mu \mathrm{g} / \mathrm{kg} /$ week & $344(48.3 \%)$ & $268(62.0 \%)$ \\
$\geq 7 \mu \mathrm{g} / \mathrm{kg} /$ week & $368(51.7 \%)$ & $164(38.0 \%)$ \\
\hline
\end{tabular}

$*: p<0.05$ versus area $\mathrm{A}$ (median test).
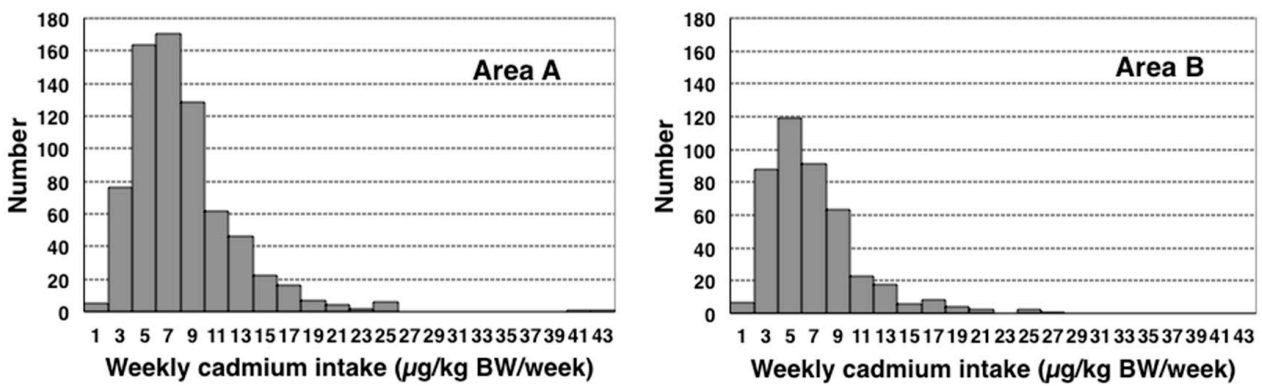

Figure 3. Distribution of weekly cadmium intake per body weight in female farmers in cadmium-polluted areas A and B in Akita, Japan.

We further divided weekly $\mathrm{Cd}$ intake per body weight into age-classified groups and examined differences between them (Table 14). In area A, weekly Cd intake per body weight was higher in subjects aged 40 or older than in younger subjects, while no significant differences were observed between age-classified groups in area B. Weekly Cd intake per body weight in subjects aged 50 or older was above PTWI or TWI in area A.

Table 14. Age-classified weekly cadmium intake per body weight ( $\mu \mathrm{g} / \mathrm{kg}$ BW/week) in female farmers in areas $\mathrm{A}$ and $\mathrm{B}$.

\begin{tabular}{|c|c|c|c|}
\hline Age Groups (Mean Age \pm SD) & $n$ & Median & 25-75th Percentile \\
\hline \multicolumn{4}{|c|}{ Area A $(n=712)$} \\
\hline $20-29$ years $(25.0 \pm 3.0)$ & 27 & 3.6 & $2.4-5.9$ \\
\hline $30-39$ years $(35.0 \pm 3.2)$ & 27 & 4.8 & $3.5-7.2$ \\
\hline $40-49$ years $(45.4 \pm 2.9)$ & 109 & $6.3^{*}$ & $4.5-8.7$ \\
\hline $50-59$ years $(54.6 \pm 2.9)$ & 213 & $7.1 *$ & $5.4-9.5$ \\
\hline $60-69$ years $(64.6 \pm 2.8)$ & 278 & $8.1^{*}$ & $6.0-11$ \\
\hline 70 years- $(72.8 \pm 2.2)$ & 58 & $7.8^{*}$ & $6.0-11$ \\
\hline \multicolumn{4}{|c|}{ Area B $(n=432)$} \\
\hline $30-39$ years $(36.8 \pm 1.5)$ & 14 & 6.3 & $4.5-14$ \\
\hline $40-49$ years $(45.8 \pm 2.7)$ & 85 & 5.1 & $3.2-7.7$ \\
\hline $50-59$ years $(54.6 \pm 2.8)$ & 151 & 5.7 & $3.9-7.5$ \\
\hline $60-69$ years $(63.9 \pm 2.8)$ & 143 & 6.8 & $5.2-9.0$ \\
\hline 70 years- $(73.1 \pm 2.8)$ & 39 & 6.6 & $5.5-11$ \\
\hline
\end{tabular}


We then performed the Monte Carlo simulation using the same data and the results obtained are shown in Figure 4. We excluded 2 outliers in area A, which markedly skewed their probability density distributions. As a result, we obtained estimated median weekly Cd intake levels of 7.0 and $6.0 \mu \mathrm{g} / \mathrm{kg}$ BW/week in areas A and B, respectively (Table 15), which were similar to the results described above.
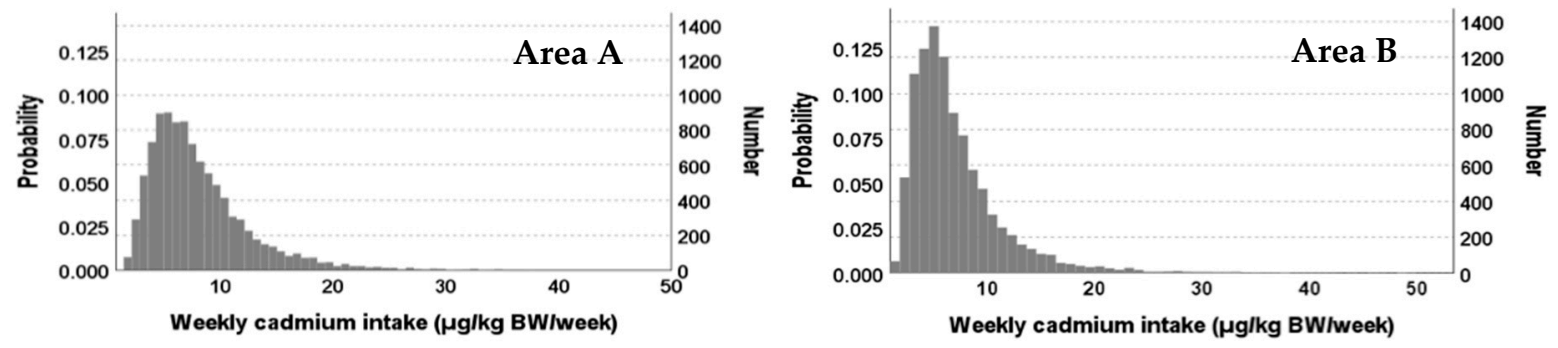

Figure 4. Probability density distributions of weekly cadmium intake per body weight in female farmers in cadmium-polluted areas A and B in Akita, Japan, estimated using the Monte Carlo simulation.

Table 15. Results of the Monte Carlo simulation for weekly cadmium intake per body weight $(\mu \mathrm{g} / \mathrm{kg} \mathrm{BW} /$ week) in female farmers in areas A and B.

\begin{tabular}{ccc}
\hline Weekly Cadmium Intake & Area A $(n=710) *$ & Area B $(\boldsymbol{n}=\mathbf{4 3 2})$ \\
\hline Median & 7.0 & 6.0 \\
5-95th percentiles & $3.1-17.0$ & $2.6-15.9$ \\
Ranges & $1.2-70.9$ & $0.9-103$ \\
\hline
\end{tabular}

*: Two outliers were excluded.

\section{Discussion}

In the present study, we collected food items from local markets in two Cd-polluted areas in Akita, Japan, measured their Cd concentrations, and attempted to accurately assess Cd intake levels in local female farmers who had been exposed to high Cd levels by calculating individual Cd intake based on data obtained from diet surveys performed in health examinations. The present results demonstrated that $\mathrm{Cd}$ intake was approximately 2.5-fold higher in our subjects than in the general population. Furthermore, weekly Cd intake per body weight, which was confirmed by the Monte Carlo simulation, were approximately the same as the PTWI of JECFA or TWI of Japan, while 38.0-51.7\% of subjects had weekly $\mathrm{Cd}$ intake per body weight that was above it.

The high Cd intake levels observed among our subjects may be attributed to high Cd concentrations in local agricultural products, particularly rice. Although $\mathrm{Cd}$ concentrations in rice in these areas (GMs of 0.158 and $0.109 \mathrm{mg} / \mathrm{kg}$ in areas A and B, respectively) were lower than the safety standard $(0.4 \mathrm{mg} / \mathrm{kg})$, they were markedly higher than the median rice Cd concentrations in Japan $(0.06 \mathrm{mg} / \mathrm{kg}$ in 1997 and 1998 and $0.05 \mathrm{mg} / \mathrm{kg}$ in 2009 and 2010) [16], and there were rice that had Cd concentrations above the safety standard ( 8.2 and $5.8 \%$ in areas $A$ and $B$, respectively). Although the intake of $C d$ was higher in area $\mathrm{A}$ than in area $\mathrm{B}$, the actual accumulated levels of $\mathrm{Cd}$ in subjects were higher in area $\mathrm{B}$ than in area $\mathrm{A}$, as demonstrated by their blood and urinary $\mathrm{Cd}$ levels (for example, urinary Cd levels in 70-79-year-old subjects were 4.90 and $9.34 \mu \mathrm{g} / \mathrm{g} \mathrm{cr}$. in areas A and B, respectively, and $2.99 \mu \mathrm{g} / \mathrm{g}$ cr. in control subjects) [5]. Since the biological half-life of Cd in humans is very long (10-30 years), blood and urinary Cd levels are stable indicators of the accumulation of Cd in the human body, particularly when the level of $\mathrm{Cd}$ that accumulates is high [1]. This discrepancy may have been due to the timing of the initiation of measures in rice farming to lower $\mathrm{Cd}$ absorption from the soil in 2002, namely, the flooding of paddy fields before and after heading during August [5,17]. Actually, the rates of rice with $\mathrm{Cd}$ concentration above the safety standard in these areas were decreased after that according to the results of intensive inspections targeted for Cd-polluted rice fields by Akita 
prefecture (Akita Prefect. Department of of Agriculture, Forestry, and Fisheries) (Supplemental Table S1). More recently, our own investigations on farmers in the areas show that the median of $\mathrm{Cd}$ concentration in their self-harvested rice from 2010 to 2018 was $0.096 \mathrm{mg} / \mathrm{kg}$ and $0.7 \%$ of them were above the safety standard ( $n=599)$ (unpublished data). These results indicate the flooding of paddy fields have effectively lowered Cd concentrations in rice from 2002 in these areas. The health examination in area A was performed in 2001-2002, at the initiation of the flooding of paddy fields, while that in area B was performed in 2002-2003, just after the flooding of paddy fields had started. Therefore, Cd intake levels may have been higher in area B than in area A before the start of the flooding of paddy fields.

$\mathrm{Cd}$ intake levels from food items other than rice and rice products, which remained constant independent of the flooding of rice paddy fields, were also higher in these areas in Akita than the average in Japan (Figure 2) [15]. Although total Cd intake other than rice and rice products in these areas was nearly twice the average in Japan in 2007; those from other food items varied [15]. Cd intake from cereals, tubers, and roots was $2.3-2.4 \mu \mathrm{g} /$ day in these areas, which is similar to the average in Japan of $2.7 \mu \mathrm{g} /$ day. On the other hand, $\mathrm{Cd}$ intake from soybeans and soybean products was $3.4 \mu \mathrm{g} / \mathrm{day}$ in these areas, which was approximately 3-fold higher than the average in Japan of $1.1 \mu \mathrm{g} /$ day. Cd intake from vegetables and seafood in the general Japanese population was reported in the classification as "brightly colored vegetables", "vegetables, seaweeds", and "seafood" by the Ministry of Agriculture, Forestry, and Fisheries. Therefore, we compared total Cd intake from vegetables and seafood in areas A and B with total Cd intake from "brightly colored vegetables", "vegetables, seaweeds", and "seafood" in the general Japanese population; the former, 12.3-13.1 $\mu \mathrm{g} / \mathrm{day}$, was higher than the latter, $8.2 \mu \mathrm{g} / \mathrm{day}$. In addition, $\mathrm{Cd}$ intake from mushrooms in these areas, 2.6-2.8 $\mu \mathrm{g} / \mathrm{day}$, which was absent from the report by the Ministry of Agriculture, Forestry, and Fisheries of Japan, significantly contributed to total $\mathrm{Cd}$ intake. These comparisons revealed that agricultural products in these areas contained high $\mathrm{Cd}$ concentrations due to $\mathrm{Cd}$ contamination in the local farmland, and the consumption of these products was a significant contributor to $\mathrm{Cd}$ overexposure among local farmers.

Among agricultural products, $\mathrm{Cd}$ concentrations were high in sesame seeds, taro (satoimo in Japanese), yams (yamaimo in Japanese), soybeans, carrot, spinach, burdock (gobo in Japanese), garland chrysanthemum (shungiku in Japanese), Japanese mustard spinach (komatsuna in Japanese), garlic, belvedere fruit (tomburi in Japanese), and shiitake mushroom. Among seafood, many types of seaweed (such as wakame, kombu, and hijiki in Japanese), salted squid guts, scallops (hotate in Japanese) and oysters (kaki in Japanese) with innards, Japanese littleneck clam (asari in Japanese), and freshwater clam (shijimi in Japanese) showed very high Cd concentrations. On the other hand, Cd concentrations were generally low in livestock food and fruit. These results are consistent with previous findings showing that $\mathrm{Cd}$ concentrations were high in tubers, soybeans, brightly colored vegetables, and seafood, particularly seaweed, and the innards of squid or shellfish in Japan [10,15].

Median weekly Cd intake levels in our subjects were 7.2 and $6.0 \mu \mathrm{g} / \mathrm{kg} \mathrm{BW} /$ week in areas A and B, respectively, which were approximately the PTWI of JECFA at that time or the current TWI in Japan of $7 \mu \mathrm{g} / \mathrm{kg}$ BW/week. In our previous study on area A, we estimated weekly Cd intake levels to be between $5.70-6.72 \mu \mathrm{g} / \mathrm{kg}$ BW/week, which was consistent with the present results, based on 2 assumptions: all food items other than rice may be contaminated by $\mathrm{Cd}$ at the same percentage contribution as rice (50\%) or at a constant level (15.0 $\mu \mathrm{g} /$ day) [4]. In addition, the percentage of subjects with weekly $\mathrm{Cd}$ intake levels higher than $7 \mu \mathrm{g} / \mathrm{kg}$ BW/week in area A, 51.7\%, in the present study was similar to previously estimated percentages, 33-51\%. These results indicate that previously estimated $\mathrm{Cd}$ intake levels, based only on $\mathrm{Cd}$ concentrations in rice and miso, were not inaccurate, and that local farmers in Cd-polluted areas in Akita exposed to $\mathrm{Cd}$ were at risk of adverse effects. Weekly Cd intake per body weight was above the PTWI or TWI in older subjects in area A, suggesting a higher risk of developing renal tubular dysfunction among the elderly. There were no age-classified subgroups above the PTWI or TWI in area B, but actually the older subjects might had been exposed to much higher levels of $\mathrm{Cd}$ like in area A before the start of the flooding of paddy fields. 
Two methods are generally employed in exposure assessments of chemicals in food: a total diet study (TDS) and individual food analysis. There are two approaches in TDS: a market basket method and duplicate portion study $[5,18]$. In the market basket method, which assesses chemical intake in divided food groups, the average intake of a chemical in a certain population may be calculated; however, the concentration of this chemical in individual food items remains unknown. On the other hand, the duplicate portion study, which measures chemical concentrations in whole meals, provides information on actual chemical intake by individuals, but does not give stable results on chemical intake. We simultaneously performed a duplicate portion study in area A on 17 female farmers for three days to support the present results, and obtained a smaller median Cd intake of $19.0 \mu \mathrm{g} /$ day that ranged between 9.8-63.1 $\mu \mathrm{g} /$ day (unpublished data). In contrast, the individual food analysis, adopted in the present study, allowed us to identify the source foods of chemical intake and calculate the average intake of a chemical in a population, similar to the market basket method. The individual food analysis generally cannot exclude uncertainties due to processing and cooking foodstuffs. However, $\mathrm{Cd}$ itself does not increase or diminish in foodstuffs by processing and cooking. Furthermore, mass changes in individual foods were included in the calculation of $\mathrm{Cd}$ intake based on the tables of mass changes in individual food, from the Standard Tables of Food Compositions in Japan (7th edition, Japanese Ministry of Education, Culture, Sports, Science, and Technology). Furthermore, a probabilistic assessment, the Monte Carlo simulation, may be performed using individual $\mathrm{Cd}$ concentrations in food items.

The National Institute of Health Sciences previously investigated Cd intake by the general Japanese population using the market basket method [15] and an assessment of $\mathrm{Cd}$ intake based on the individual food analysis, similar to the present study, was not previously performed in Japan. Cd intake in the Jinzu River basin of Toyama, the heaviest Cd-polluted area in Japan, was reported to be as high as $600 \mu \mathrm{g} /$ day in 1968 using the market basket method [19]. On the other hand, in Kosaka town in Akita, the intake of $\mathrm{Cd}$ from rice by local residents, assessed from Cd concentrations in rice, was $100.6 \mu \mathrm{g} /$ day in 1974-1976 [20], $92 \mu \mathrm{g} /$ day in 1978, and $55 \mu \mathrm{g} /$ day in 1999-2000 using the duplicate portion study [19]; the latter was similar to the present results. These findings indicate that $\mathrm{Cd}$ intake in Cd-polluted areas in Akita has been decreasing for decades, and are consistent with the present results. Cd intake in Cd-polluted areas in Akita is still higher than those by the general Japanese population and Western counties. Recent $\mathrm{Cd}$ intake by general populations assessed using the market basket method was $4.63 \mu \mathrm{g} /$ day or $0.54 \mu \mathrm{g} / \mathrm{kg}$ body weight $/$ week in U.S.A. [21], $0.16 \mu \mathrm{g} / \mathrm{kg}$ body weight/week in France [22], $0.77 \mu \mathrm{g} / \mathrm{kg}$ body weight/week in Spain [23], $1 \mu \mathrm{g} / \mathrm{kg}$ body weight/week in Sweden [24], $5.00 \mu \mathrm{g} / \mathrm{day}$ in Italy [25], $0.85 \mu \mathrm{g} / \mathrm{kg}$ body weight/week in Belgium [26], and $13.5 \mu \mathrm{g} /$ day in Denmark [27]. Although Cd intake in Eastern Asian countries, where rice is consumed as a staple food, is generally high, such as $32.7 \mu \mathrm{g} /$ day in China [28] and $22.0 \mu \mathrm{g} /$ day in Korea [29], Cd intake levels remain higher in Akita.

There are some limitations in the present study. The data used in this study were obtained in 2001-2003. Nevertheless, the results obtained remain important, even after approximately 20 years, because few Cd-polluted areas remain in Japan. Furthermore, data were collected at the start of the flooding of paddy fields, which has successfully decreased Cd exposure levels in farmers in these areas; therefore, these data will never be obtained again in the future.

Furthermore, the subjects examined were females and therefore the $\mathrm{Cd}$ intake by male farmers remains unknown. Cd intake levels by males may be higher than those by females based on differences in the amount of food consumed. However, since females are generally more vulnerable to $\mathrm{Cd}$ toxicity than males, such as higher intestinal Cd absorbability in females than in males, it is not inappropriate to use the results of the present study for risk assessments of $\mathrm{Cd}$ in the general population. In area $\mathrm{B}$, the results of the $\mathrm{Cd}$ exposure assessment did not reflect previous $\mathrm{Cd}$ intake because of the flooding of paddy fields. However, the Cd intake level in area B was still higher than that by the general population. In DHQ, which assesses general nutritional intake, some food items that showed markedly higher $\mathrm{Cd}$ concentrations were absent, such as kelp and hijiki. Therefore, we were unable to include $\mathrm{Cd}$ intake from these foods in total $\mathrm{Cd}$ intake, which may have led to the underestimation of $\mathrm{Cd}$ exposure. 
The Japanese government provides $\mathrm{Cd}$ intake values by the general population as averages. Although median values in Cd-polluted areas cannot be statistically compared to these averages, the differences are large enough to identify areas at risk of health problems.

\section{Conclusions}

We performed an exposure assessment of $\mathrm{Cd}$ in female farmers, who are more vulnerable to $\mathrm{Cd}$ toxicity than males in Cd-polluted areas in Akita, Japan. Participants underwent local health examinations during 2001-2004, using the individual food analysis method with the Monte Carlo simulation. Results showed that $\mathrm{Cd}$ intake was higher than that by the general population, which was derived from local agricultural products, particularly rice, and also that their exposure levels to $\mathrm{Cd}$ were approximately the PTWI of JECFA or TWI of Japan.

Supplementary Materials: The following are available online at http://www.mdpi.com/2305-6304/8/2/44/s1, Table S1: Annual trend of rates of rice with a cadmium concentration above the safety standard $(0.4 \mathrm{mg} / \mathrm{kg})$ in the intensive inspections targeted for 3 cadmium-polluted areas in Akita prefecture, Japan, around the start of the flooding of paddy fields (2002).

Author Contributions: Formulating study protocols, F.K., H.H., and E.O.; collecting food items, H.H. and E.O.; health examinations, F.K., H.H., E.O., Y.H., S.S., and K.M.; advising about the diet study, S.S.; data curation, H.H.; statistical analyses, H.H. and A.O.; writing-original draft preparation, H.H.; visualization, H.H. and A.O.; funding acquisition, F.K. and H.H. All authors have read and agreed to the published version of the manuscript.

Funding: This research project was supported by grants mainly from the Ministry of Health, Labor, and Welfare and the Ministry of Agriculture and Forestry of Japan, and in part from CREST-JST and a Grant-in-Aid for Scientific Research (B) [20H03945] from the Ministry of Education, Science, and Culture of Japan.

Acknowledgments: The authors express special gratitude to JA Akita Kita and Kosaka Municipal Government as well as the subjects of this study for their corporation, to Shin Hasebe and Hinako Togashi for their guidance when collecting food items from local markets, to Koji Matsuno for measuring Cd concentrations in samples for the duplicate portion study, and Kentaro Murakami and Hitomi Okubo for helping with diet surveys.

Conflicts of Interest: The authors declare no conflicts of interest.

\section{References}

1. Nordberg, G.F.; Nogawa, K.; Nordberg, M. Cadmium. In Handbook on the Toxicology of Metals, 4th ed.; Nordberg, G.F., Fowler, B.A., Nordberg, M., Eds.; Academic Press: Burlington, MA, USA, 2015; pp. 667-716.

2. Aoshima, K. Recent clinical and epidemiological studies of itai-itai disease (cadmium-Induced renal tubular osteomalacia) and cadmium nephropathy in the Jinzu River basin in Toyama prefecture, Japan. In Cadmium Toxicity; Himeno, S., Aoshima, K., Eds.; Springer: Singapore, 2019; pp. 23-37.

3. Horiguchi, H. Cadmium exposure and its effects on the health status of rice farmers in Akita prefecture. In Cadmium Toxicity; Himeno, S., Aoshima, K., Eds.; Springer: Singapore, 2019; pp. 75-83.

4. Horiguchi, H.; Oguma, E.; Sasaki, S.; Miyamoto, K.; Ikeda, Y.; Machida, M.; Kayama, F. Dietary exposure to cadmium at close to the current provisional tolerable weekly intake does not affect renal function among female Japanese farmers. Environ. Res. 2004, 95, 20-31. [CrossRef]

5. Horiguchi, H.; Oguma, E.; Sasaki, S.; Okubo, H.; Murakami, K.; Miyamoto, K.; Hosoi, Y.; Murata, K.; Kayama, F. Age-relevant renal effects of cadmium exposure through consumption of home-harvested rice in female Japanese farmers. Environ. Int. 2013, 56, 1-9. [CrossRef]

6. Sasaki, T.; Horiguchi, H.; Arakawa, A.; Oguma, E.; Komatsuda, A.; Sawada, K.; Murata, K.; Yokoyama, K.; Matsukawa, T.; Chiba, M.; et al. Hospital-based screening to detect patients with cadmium nephropathy in cadmium-polluted areas in Japan. Environ. Health Prev. Med. 2019, 24, 8. [CrossRef] [PubMed]

7. WHO (World Health Organization). Cadmium. In Evaluation of Certain Food Additives and Contaminants; WHO Technical Report Series 960; WHO: Geneva, Italy, 2011; pp. 149-162.

8. Gibney, M.J.; van der Voet, H. Introduction to the Monte Carlo project and the approach to the validation of probabilistic models of dietary exposure to selected food chemicals. Food Addit. Contam. 2003, 20 (Suppl. 1), S1-S7. [CrossRef] [PubMed] 
9. Horiguchi, H.; Oguma, E.; Sasaki, S.; Miyamoto, K.; Ikeda, Y.; Machida, M.; Kayama, F. Comprehensive study of the effects of age, iron deficiency, diabetes mellitus, and cadmium burden on dietary cadmium absorption in cadmium-exposed female Japanese farmers. Toxicol. Appl. Pharmacol. 2004, 196, 114-123. [CrossRef]

10. Ishizaki, A.; Fukushima, M.; Sakamoto, M. Distribution of $\mathrm{Cd}$ in biological materials. 2. Cadmium and zinc contents of foodstuffs. Jpn. J. Hyg. 1970, 25, 207-222, (In Japanese with an English abstract). [CrossRef]

11. Sasaki, S.; Yanagibori, R.; Amano, K. Self-administered diet history questionnaire developed for health education: A relative validation of the test-version by comparison with 3-day diet record in women. J. Epidemiol. 1998, 8, 203-215. [CrossRef]

12. Sasaki, S.; Yanagibori, R.; Amano, K. Validity of a self-administered diet history questionnaire for assessment of sodium and potassium: Comparison with single 24-hour urinary excretion. Jpn. Circ. J. 1998, 62, 431-435. [CrossRef]

13. Sasaki, S.; Ushio, F.; Amano, K.; Morihara, M.; Todoriki, O.; Uehara, Y.; Toyooka, E. Serum biomarker-based validation of a self-administered diet history questionnaire for Japanese subjects. J. Nutr. Sci. Vitaminol. 2000, 46, 285-296. [CrossRef]

14. Masironi, R.; Koirtyohann, S.R.; Pierce, J.O. Zinc, copper, cadmium and chromium in polished and unpolished rice. Sci. Total Environ. 1977, 7, 27-43. [CrossRef]

15. Ministry of Agriculture, Forestry and Fisheries. Cadmium Concentrations in Agricultural Products in Japan. (In Japanese). Available online: https://www.maff.go.jp/j/syouan/nouan/kome/k_cd/jitai_sesyu/01_inv.html (accessed on 31 March 2020).

16. Aoshima, K.; Horiguchi, H. Historical lessons on cadmium environmental pollution problems in Japan and current cadmium exposure situation. In Cadmium Toxicity; Himeno, S., Aoshima, K., Eds.; Springer: Singapore, 2019; pp. 3-19.

17. Arao, T.; Ishikawa, S.; Murakami, M.; Abe, K.; Maejima, Y.; Makino, T. Heavy metal contamination of agricultural soil and countermeasures in Japan. Paddy Water Environ. 2010, 8, 247-257. [CrossRef]

18. Ministry of Agriculture, Forestry and Fisheries. The Guideline for Total Diet Study. (In Japanese). Available online: https://www.maff.go.jp/j/syouan/seisaku/risk_analysis/tds/ (accessed on 31 March 2020).

19. Ikeda, M.; Ezaki, T.; Tsukahara, T.; Moriguchi, J. Dietary cadmium intake in polluted and non-polluted areas in Japan in the past and in the present. Int. Arch. Occup. Environ. Health 2004, 77, 227-234. [CrossRef] [PubMed]

20. Haga, Y.; Kobayasi, T.; Otani, H.; Miura, H.; Kato, A.; Saruta, T. Environmental and medical investigation on the pollution of heavy metal, No.6. Rep. Akita Pref. Inst. Public Health 1978, 22, 135-139. (In Japanese)

21. Kim, K.; Melough, M.M.; Vance, T.M.; Noh, H.; Koo, S.I.; Chun, O.K. Dietary Cadmium Intake and Sources in the US. Nutrients 2018, 11, 2. [CrossRef]

22. Arnich, N.; Sirot, V.; Rivière, G.; Jean, J.; Noël, L.; Guérin, T.; Leblanc, J.C. Dietary exposure to trace elements and health risk assessment in the 2nd French Total Diet Study. Food Chem. Toxicol. 2012, 50, 2432-2449. [CrossRef]

23. Marín, S.; Pardo, O.; Báguena, R.; Font, G.; Yusà, V. Dietary exposure to trace elements and health risk assessment in the region of Valencia, Spain: A total diet study. Food Addit. Contam. Part A Chem. Anal. Control Expo. Risk Assess 2017, 34, 228-240. [CrossRef]

24. Sand, S.; Becker, W. Assessment of dietary cadmium exposure in Sweden and population health concern including scenario analysis. Food Chem. Toxicol. 2012, 50, 536-544. [CrossRef]

25. Filippini, T.; Cilloni, S.; Malavolti, M.; Violi, F.; Malagoli, C.; Tesauro, M.; Bottecchi, I.; Ferrari, A.; Vescovi, L.; Vinceti, M. Dietary intake of cadmium, chromium, copper, manganese, selenium and zinc in a Northern Italy community. J. Trace Elem. Med. Biol. 2018, 50, 508-517. [CrossRef]

26. Vromman, V.; Waegeneers, N.; Cornelis, C.; De Boosere, I.; Van Holderbeke, M.; Vinkx, C.; Smolders, E.; Huyghebaert, A.; Pussemier, L. Dietary cadmium intake by the Belgian adult population. Food Addit. Contam. Part A Chem. Anal. Control Expo. Risk Assess 2010, 27, 1665-1673. [CrossRef] [PubMed]

27. Vacchi-Suzzi, C.; Eriksen, K.T.; Levine, K.; McElroy, J.; Tjønneland, A.; Raaschou-Nielsen, O.; Harrington, J.M.; Meliker, J.R. Dietary Intake Estimates and Urinary Cadmium Levels in Danish Postmenopausal Women. PLoS ONE 2015, 10, e0138784. [CrossRef] [PubMed] 
28. Xiao, G.; Liu, Y.; Dong, K.F.; Lu, J. Regional characteristics of cadmium intake in adult residents from the 4th and 5th Chinese Total Diet Study. Environ. Sci. Pollut. Res. Int. 2020, 27, 3850-3857. [CrossRef] [PubMed]

29. Kim, H.; Lee, J.; Woo, H.D.; Kim, D.W.; Choi, I.J.; Kim, Y.I.; Kim, J. Association between dietary cadmium intake and early gastric cancer risk in a Korean population: A case-control study. Eur. J. Nutr. 2019, 58, 3255-3266. [CrossRef] [PubMed]

(C) 2020 by the authors. Licensee MDPI, Basel, Switzerland. This article is an open access article distributed under the terms and conditions of the Creative Commons Attribution (CC BY) license (http://creativecommons.org/licenses/by/4.0/). 